\section{Between decay and repair: Embodied experiences of infrastructure's materiality}

EPE: Nature and Space

Article reuse guidelines: sagepub.com/journals-permissions DOI: I0.I I 77/25 I 4848620980597 journals.sagepub.com/home/ene

@SAGE

\title{
Kavita Ramakrishnan
}

University of East Anglia, UK

\section{Kathleen O'Reilly}

Texas A\&M University, USA

\section{Jessica Budds}

University of East Anglia, UK

\section{Keywords}

Infrastructural change, materiality, labor, embodiment, maintenance, affect

This special issue bridges human geography, anthropology and political ecology to understand infrastructure in between conditions of decay and repair, and how embodied experiences of infrastructure intersect with processes of socio-spatial transformation. Our focus on decay and repair builds on literature that understands infrastructure as material processes articulated through social and affective dimensions, with implications for infrastructural access and broader political claims (Anand, 2015; Barnes, 2017; Chalfin, 2019; Fredericks, 2018; Lemanski, 2020; Schwenkel, 2015; von Schnitzler, 2013). We seek to further develop insight into and connect the multiple registers of discourse, materiality, labor and power geometries that determine when, and in what instances, infrastructures are unmade and remade. Decay and repair index the unpredictable socio-ecological relations that are created and animated by infrastructure, and how such relationships are further challenged and sustained by expectations of and capacities for maintenance. Though decay and repair are framed as a binary, we seek to capture the fluctuation between the two, and what happens in between.

The collection contributes to recent scholarship on the everyday experiences of infrastructure among ordinary people (Anand et al., 2018; Graham and McFarlane, 2015; McFarlane and Silver, 2017; Simone, 2004), by specifically foregrounding political 
economy, embodiment and socio-ecological relations. Following both Collard et al. (2018) and Doshi (2017), the seven articles examine the social-material processes that produce uneven spatial arrangements, enabling us to understand whose lives are neglected or improved through networks of infrastructure. Therefore, our focus on infrastructural decay and repair seeks to make visible the subjectivities, social relations and power imbued in infrastructure and its wider configurations. Working as more than metaphor, decay and repair allow us to conceptualize the particular spatio-temporalities of infrastructures in transition and their associated meanings; moreover, as interrogative devices, they reveal how affective experiences of infrastructure are connected to wider processes of social reproduction and political contestation. Thus, decay and repair capture the dialectical and relational processes between infrastructure and affective experiences, across intersecting axes of social difference, with implications for social change and justice.

In this way, we begin to answer the question posed by the editors of this journal in their introduction to the first issue: "what theories and methodologies can expose "underground connections" that affect how different social groups, places and natures are unevenly subject to violence and oppression?' (Collard et al., 2018: 13). The articles in this issue comprise a subset of papers presented and discussed at a workshop entitled 'Processes of Decay and Repair: Ecologies of Life, Politics and Urban Infrastructure', held at the University of East Anglia in May 2018. Thus, our motivating questions behind this issue are the following: (1) Which infrastructures decay or are repaired, under what conditions and by/for whom?; (2) What are the dialectical relationships between socio-natures and lived realities, which emerge through processes of decay and repair?; (3) What meanings and affective conditions are generated through processes of decay and repair?

We reorient our investigations of infrastructures that are continually transitioning between decay and repair to the body and particular configurations of corporeality, following Doshi's (2017) observation that these are largely neglected in conceptualizations of urban infrastructure and politics (also see Chalfin, 2019; Fredericks, 2018). We thus center not only the body and the processes within and surrounding it vis-à-vis infrastructure, but also the social codes and relations that keep the body connected to infrastructure, or demand particular types and/or certain divisions of labour, often reinforcing or remaking gendered, classed and/or racialized lines. By emphasizing ethnographic work, we ask how particular configurations of the wider political economy, embodiment and affect, and socioecological relations can shift subjectivities and negotiations of infrastructure in ways that offer emancipatory potential.

The collection starts with a theoretical intervention into infrastructural decay, maintenance and repair by Kavita Ramakrishnan, Kathleen O'Reilly and Jessica Budds, 'The temporal fragility of infrastructure: Theorizing decay, maintenance and repair', which develops the concept of temporal fragility to describe the dynamic and emergent nature of infrastructure's material condition and its contingent social relations. The approach aims to capture how the processes of unmaking and remaking infrastructure shape embodied labor, differentiated citizenship and socio-ecological relations in particular ways, thereby shedding light on how people resist and challenge infrastructural determinacy and anticipate social justice.

'The body as infrastructure', by Luis Andueza, Archie Davies, Alex Loftus and Hannah Schling, explores the laboring body on a metabolic level, lending insight into wider questions of social reproduction and capital accumulation. Their Marxist-feminist approach fills a gap in literature on urban infrastructures by disclosing the decay and repair of bodies as part of a circulatory system where bodies that labor are supported by calories produced by other, specific bodies, as in their example of women cooking for working men. Infrastructural 
knowledge and practices are mapped onto bodies, with different approaches to repair adopted by social groups over time and space (Edensor, 2011). This embodied labor includes infrastructural repair undertaken by ordinary individuals (Anand, 2015), expected from the state (Lemanski, 2020), or dependent on community members (Schwenkel, 2015). The article by Noura Wahby, entitled 'Urban informality and the state: Repairing Cairo's waters through Gehood Zateya', demonstrates a mix of these three actors, as she shows how both marginalized and elite residents in Cairo draw on social connections to keep their water infrastructure functioning. Furthermore, in Thomas Cowan's, 'The village as urban infrastructure: Social reproduction, agrarian repair and uneven urbanisation', the village itself is infrastructural, and its inhabitants are "differently decaying" as the city of Gurgaon transforms rapidly around them. Through networks and class-based hierarchies, land-owning "peasant-rentiers" within the village initiate regimes of repair that ensure further uneven accumulation of capital, and anticipate decay by fending off the constant threat of dispossession as buildable land grows scarce.

A second lens framing decay and repair in this special issue is political economy, which considers how these processes transform state-citizen relations. The state can strategically use decay to hasten processes of eviction, dispossession and abandonment (Chu, 2014). There may also be a lack of intentionality on the part of the state, where neglect and disinvestment occur over time - processes that are still violent but operate with different logics. Yaffa Truelove and Kathleen O'Reilly's article, 'Making India's cleanest city: Sanitation, intersectionality, and infrastructural violence', demonstrates the first, eviction, whereby the Clean India Mission in Indore has been utilized to destroy the housing of the urban poor, and paradoxically, demolish newly built sanitation infrastructure, in the name of eradicating open defecation. Truelove and O'Reilly use the concept of 'infrastructural intersectionality' to consider how social networks and material infrastructure are interwoven, and thus simultaneously made and unmade. Again, Noura Wahby's article shows how it is the practices of water infrastructure maintenance that blur boundaries between formal and informal provision, as residents of both informal settlements and gated communities negotiate from different citizen-subject positionalities with the state in order to access water.

Finally, we interrogate decay and repair through a focus on socio-ecological relations, and it is here too that intersectionality remains a connecting thread. Jonathan Silver, in 'Decaying infrastructures in the post-industrial city: An urban political ecology of the US pipeline crisis', repoliticizes socio-natures through the lens of racial capitalism in Camden, New Jersey, where predominantly Black residents bear the toxic effects of decaying pipeline infrastructure following privatization. Water leaks resulting from decay exemplify the unbounding of socio-natures from attempts to control them, including an emerging activism to contest further breakdown. With a similar focus on socio-natures, Patrick Bresnihan and Arielle Hesse in their article 'Political ecologies of infrastructural and intestinal decay', examine cryptosporidium contamination of public water supplies in rural Ireland, and how it mobilizes particular forms of repair work; socio-natures here become bound up with contestations over payment, suffering bodies and wider visions of a modern Ireland.

Similar to Graham and McFarlane (2015), the articles in the issue reject infrastructure as something that is conceptually, and in everyday life, straightforward. Decay and repair offer one way of adding necessary complexity to our current understandings of infrastructure, especially through situated case studies rooted in everyday experiences. For instance, a focus on lived experiences may trouble the ready (and normative) demarcation of decay as 'bad' and repair as 'good' (DeSilvey, 2006), highlighting, for example, opportunities created by decaying infrastructure for challenging state power, and producing new forms of contestation. Thus, this special issue opens up how infrastructure - with its varied conditions, 
meanings, and subjectivities - fluctuates between decay and repair and what it means for ordinary people and everyday spatial dynamics.

\section{Highlights}

- We examine infrastructure in between conditions of decay and repair, and how embodied experiences of infrastructure intersect with spatial transformation.

- Decay and repair capture the dialectical and relational processes between infrastructure and affective experiences, across intersecting axes of social difference.

- We open up how infrastructure fluctuates between decay and repair and what it means for ordinary people.

\section{Acknowledgements}

We would like to thank the University of East Anglia, School of International Development, for funding and hosting the workshop 'Processes of Decay and Repair: Ecologies of Life, Politics and Urban Infrastructure' in May 2018, and to all the participants whose generative ideas helped shape this issue. Finally, thank you to Leila Harris and Nik Heynen for supporting this issue.

\section{Declaration of conflicting interests}

The author(s) declared no potential conflicts of interest with respect to the research, authorship, and/ or publication of this article.

\section{Funding}

The author(s) disclosed receipt of the following financial support for the research, authorship, and/or publication of this article: The University of East Anglia, School of International Development, for providing funding for the workshop that generated this special issue and supplementary funding from the Department of Geography at Texas A\&M University.

\section{References}

Anand N (2015) Leaky states: Water audits, ignorance, and the politics of infrastructure. Public Culture 27(2(76)): 205-330.

Anand N, Gupta A and Appel H (2018) The Promise of Infrastructure. Durham, NC: Duke University Press.

Barnes J (2017) States of maintenance: Power, politics and Egypt's irrigation infrastructure. Environment and Planning D: Society and Space 35(1): 146-164.

Chalfin B (2019) Waste work and the dialectics of precarity in urban Ghana: Durable bodies and disposable things. Africa 89(3): 499-520.

Chu J (2014) When infrastructures attack: The workings of disrepair in China. American Ethnologist 41(2): 351-367.

Collard R, Harris LM, Heynen N, et al. (2018) The antinomies of nature. Environment and Planning E: Nature and Space 1(1-2): 1-22.

DeSilvey C (2006) Observed decay: Telling stories with mutable things. Journal of Material Culture 11(3): 318-338.

Doshi S (2017) Embodied urban political ecology: Five propositions. Area 49(1): 125-128.

Edensor T (2011) Entangled agencies, material networks and repair in a building assemblage: The mutable stone of St. Ann's Church, Manchester. Transactions of the Institute of British Geographers 36(2): $238-252$.

Fredericks R (2018) Garbage Citizenship: Vital Infrastructures of Labor in Dakar, Senegal. Durham: Duke University Press. 
Graham S and McFarlane C (2015) Infrastructural Lives: Urban Infrastructure in Context. London: Routledge.

Lemanski C (2020). Infrastructural citizenship: The everyday citizenships of adapting and/or destroying public infrastructure in Cape Town, South Africa. Transactions of the Institute of British Geographers 45(3): 589-605.

McFarlane C and Silver J (2017) Navigating the city: Dialectics of everyday urbanism. Transactions of the Institute of British Geographers 42(3): 458-471.

Schwenkel C (2015) Spectacular infrastructure and its breakdown in socialist Vietnam. American Ethnologist 42(3): 520-534.

Simone A (2004) People as infrastructure: Intersecting fragments in Johannesburg. Public Culture 16(3): 407-429.

von Schnitzler A (2013) Traveling technologies: Infrastructure, ethical regimes, and the materiality of politics in South Africa. Cultural Anthropology 28(4): 670-693. 